\title{
Integrating Edmodo into Foreign Language Classes as an Assessment Tool
}

\author{
Emrah EKMEKÇi் \\ ELT Department, Ondokuz Mayıs University, Samsun, Turkey
}

\begin{abstract}
Due to the everlasting and rapid developments in educational technology, teachers are in search of exploring innovative techniques in order to promote today's students' involvement in foreign language learning process. The reason for this is that today's students are regarded as digital-natives who are difficult to motivate if modern technology they are familiar with is not utilized effectively in the classes. The absence of recent technology in classes may turn the learning process into a dull and mediocre activity. When it comes to the assessment part of this process, the situation may become worse as most of the students feel unwilling and reluctant to be assessed. Therefore, the current study is important in that it presents an innovative way of assessing students' skills they gain during language learning. For assessing students' language skills, the study introduces Edmodo, which is an educational social network providing a secure learning platform for learners and educators. It may be an effective tool with its userfriendly and practical aspects. Being a web-based online technology, Edmodo allows students and teachers to post materials, share videos and links, grades, notices, and assignments. With its practical interface, it resembles to other popular Course Management Systems (CMS). It enables teachers to work with their learners in real time, and can be used either in the class or at home. Thanks to a special code assigned for a particular group, students can interact only with their teachers and each other, which makes it secure and safe in use. In addition, parents can have their own codes to check or work together with young learners in particular. The current study is a descriptive one focusing on how to integrate Edmodo into foreign language classes as an assessment tool. The main objective of the study is to introduce the implementation of various assessment applications through Edmodo and offer some suggestions. To this end, accounts of previous experiences and some reflections of students are presented. 62 students attending English preparatory classes in a state university in Turkey participated in various assessment activities through Edmodo during 2014-2015 academic year. Reflections of the students regarding the use of Edmodo as an assessment tool were obtained through semi-structured interviews conducted by the researcher. The results indicated that most of the students found Edmodo to be funny, motivating, user-friendly, and practical. They also stated that Edmodo reduced their test anxiety to a great extent and they would prefer to be assessed through Edmodo rather than traditional assessment techniques like pen-and-paper tests.
\end{abstract}

\footnotetext{
*E-mail: emrah.ekmekci@omu.edu.tr
} 
Key Words: assessment, Edmodo, Course management system, foreign language classes

\section{Introduction}

Recent developments in information and communication technologies (ICT) have led teachers to create contemporary learning environment modernizing current teaching techniques, materials, methods, assessment tools and etc. There is no doubt that the reason behind the desire to renew this educational context is today's students' close integration with ICT. Labelled as digital-natives, today's students need more than what traditional classrooms present. Technological devices facilitating access to information anytime and anywhere have become indispensable for these students. Students can send and receive e-mails, surf on the net, use online learning platforms and follow the course content through their mobile phones. That is why teachers are in constant search of exploring innovative techniques to promote today's students' involvement in foreign language learning process in particular. In order to keep students engaged in the lessons and make them more autonomous learners, teachers have started to employ various techniques, and accordingly recent research has focused on blended learning techniques which combine online and traditional classroom-based teaching and hybrid learning mixing online and face-to-face teaching techniques. (Kandappan Balasubramanian, Jaykumar and Fukey, 2014; Batsila, Tsihouridis and Vavougios, 2014; Dogoriti and Pange, 2014; Ractham and Chen, 2013; Horvat, Dobrota, Krsmanovic and Cudanov, 2015; Al-Said, 2015).

Motivating and engaging today's students in learning process is really difficult if the learning environment does not appeal to them. When the assessment is regarded as an essential component of the process, motivating students becomes more challenging and difficult. The existence of language test anxiety in the assessment process has been proved by many scholars. That is why a great bulk of research attention has been paid to foreign language anxiety and language test anxiety. Test anxiety on different language skills has been reported by many researchers. For example, Huang and Hung (2013) explore the relationship between test anxiety and the performance of integrated tasks and speaking task in particular. They suggest that the advantage of integrated tasks over independent tasks may not be related to the reduction of test anxiety. Likewise, Lee and Lee (2015) examine the effects of audio-visual aids on anxiety, retention in reading, comprehension test scores in English as a Foreign Language (EFL) classrooms. They conclude that employing audio-visual aids can help students reduce reading and listening test anxiety. In another study analysing the factors affecting the level of test anxiety among EFL learners at elementary schools, Aydin (2013) states that young language learners have a low level of test anxiety, while they have medium level anxiety in some specific situations. Cheng and Klinger, Fox, Doe, Jin and Wu (2014) examine test anxiety from a broader perspective covering three context: The Canadian Academic English Language (CAEL), the College English Test (CET), and the General English Proficiency Test (GEPT). The study finds out that motivation and test anxiety can be related to test performance. In a similar study based on language test anxiety, Aldhafri, Alkharusi and Al Ismaili (2015) try to explore the effects of two learning strategies on students' level of test anxiety. The results of the study reveal that as the students use two strategies related to memorization and critical thinking, their level of test anxiety decreases. In another study, Salahi and Marefat (2014) investigate the effect of foreign language and test anxiety on students' test performance. They find out that both types of anxiety have negative effects on students' test performance. The researchers recommend language teachers to create more friendly and supportive atmosphere in their classes in order to decrease students' anxiety 
levels and they should also encourage students' involvement in class activities.

As it is clear from the above-mentioned studies conducted in different contexts about foreign language anxiety in general and test anxiety in particular, reducing students' anxiety levels in foreign language classrooms is crucial for success. Language teachers usually employ different formative assessment techniques and a variety of testing types during learning process. At the end of each unit, module, or chapter, students are given a quiz or a short test covering the main points of the lesson. Recently published course books have already module, unit or section quizzes. For this reason, language learners confront much more assessment activity than other subject learners. It seems quite natural for them to be anxious as they are assessed almost during the whole process. Therefore, language teachers should know how to cope with anxiety problems inside the class especially during testing their students since anxiety has the potential of decreasing students' motivation, integration, and involvement in learning. The current study, therefore, suggests an alternative way of assessing students' different language skills encouraging the use of modern technology with which almost all students are familiar. This alternative assessment tool is embedded in a learning management system (LMS) called EDMODO which is a user-friendly and popular platform. The next section focuses on learning management systems in general and then EDMODO as an assessment tool is presented.

\section{Learning Management Systems}

LMSs are mainly used to control and arrange learning and teaching activities in elearning environment. They are employed for posting content, sharing course materials and presentations, assigning students, assessments, creating quizzes, conducting polls and etc. They are also called virtual learning environment (VLE) or course management systems (CMS). In addition to administrative aspect of LMSs, they provide learners with synchronous communication facilities through chat rooms, whiteboards, video conferencing, walls and with a synchronous communication such as quizzes, polls, forums, surveys, and etc. (Conradie, Moller and Faleni, 2015). Most of the features of LMSs can be effectively used to enhance students' motivation and they increase students' academic success compared to the students who do not use e-learning platforms (Govender and Grayson, 2007). LMSs are also reported to create an informal and relaxing atmosphere by making the learning process effective (Dalton, 2009). They help learners enhance their cooperative and collaborative skills with self-directed and self-regulated nature. However, some other studies criticize the use of LMSs in that they do not provide motivation, personalization, and enthusiasm. They also hinder students' pedagogical progress with their default settings and familiar features (Naveh, Tubin and Pliskin, 2010; Lane, 2009).

\section{Edmodo as an Assessment Tool}

Edmodo is a free of charge social learning platform which provides learners with access to course content presented by teachers. It helps students interact with each other and teachers through instant messages, thus enabling learners to cooperate and collaborate in virtual classroom environment. Teachers can easily assign students and set a deadline for homework. It is a secure platform since students can only login with the special code provided by teachers. Parents can also monitor students' progress and check their homework with another special code created only for them. The first step to use Edmodo is to create a free 
account by clicking on the link 'I'm a Teacher'. The following screenshot illustrates the welcoming page of the platform.

Figure 1: Welcoming Page of the Platform

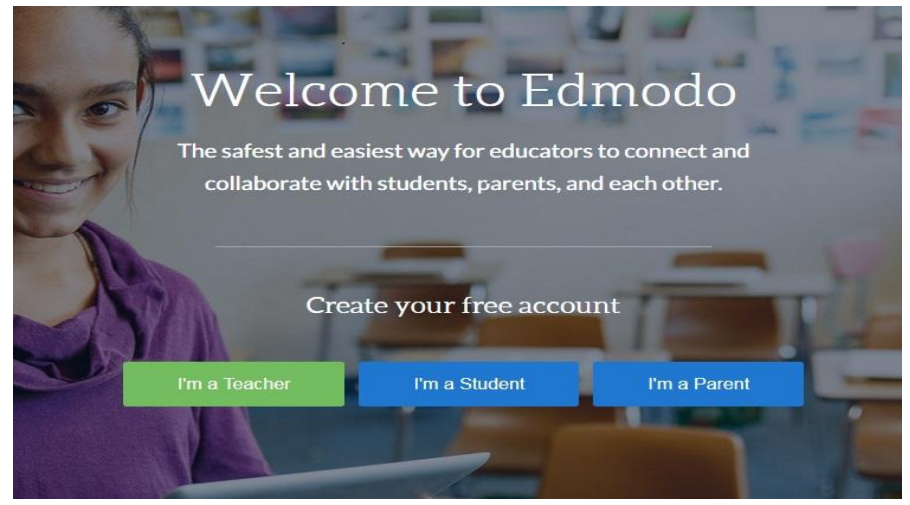

Subsequent to creating the free account, teachers are now ready to form groups. The following screenshot indicates the interface of creating and naming the new group together with selecting a grade and subject area.

Figure 2: Interface of Creating and Naming the New Groups

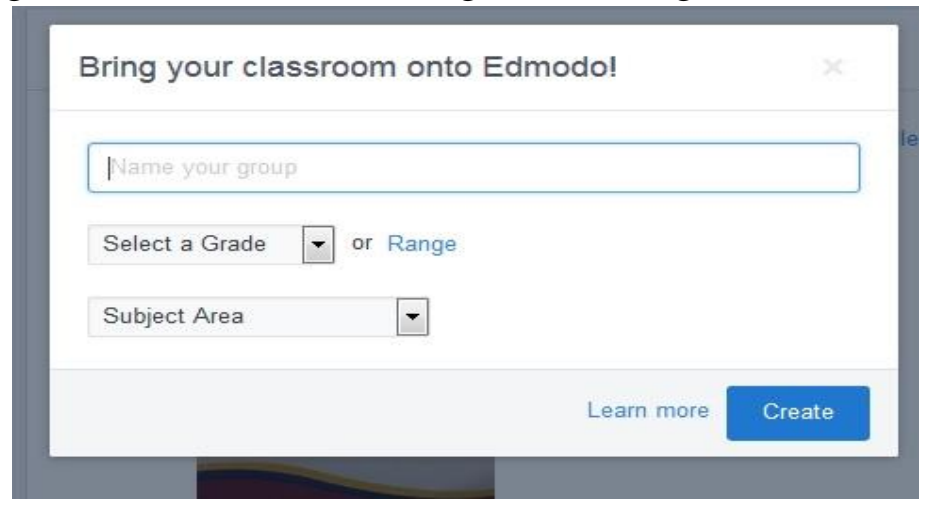

On the left side of Edmodo screen, teachers can see all groups they have created. In addition, they can find 'Manage Group', 'Create Group', and 'Join Group' buttons on this page. Loading assignments and setting a due date are among the main functions of Edmodo. Teachers can send note adding both new files, links and from the library. They can select either a special group or all groups to send the files and notes. 'Note', 'Assignment', 'Quiz', and 'Poll' sections are illustrated in the following screenshot.

Figure 3: 'Note', 'Assignment', 'Quiz', and 'Poll' Sections of the Platform

\begin{tabular}{|c|c|c|c|c|c|}
\hline एu Note & () Assignment & (2) Quiz & Il. Poll & & \\
\hline \multicolumn{6}{|c|}{ Type your note here... } \\
\hline \multicolumn{4}{|c|}{ Type the name of a group, student, or teacher... } & & Q \\
\hline 国 $\mathcal{O}$ & (). & & & Cancel or & Send \\
\hline
\end{tabular}


'Poll' section enables teachers to conduct surveys based on a question and various answers. It can be used to assess course satisfaction, needs analysis, and expectations of the students about the course. The focus of this paper is to introduce Edmodo as an assessment tool. Therefore, 'Quiz' section is attached much imporatance and will be explained with more details. When the 'Quiz' section is clicked, the following screen appears;

Figure 4: 'Create a Quiz' Section of the Platform

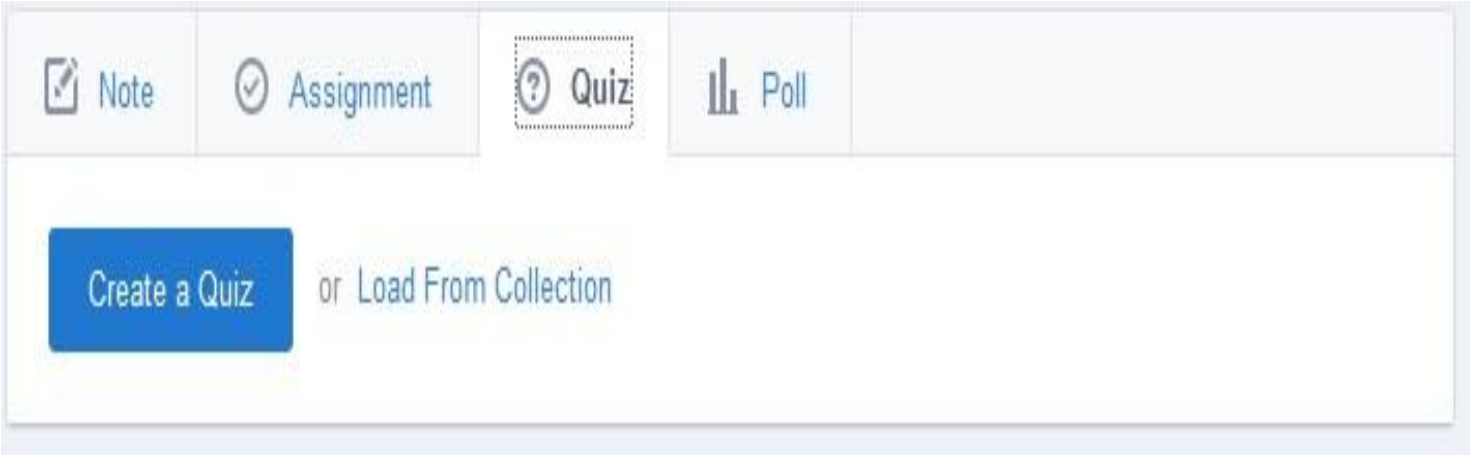

When the button 'Create a Quiz' is clicked, the following screen comes and teachers can first name the quiz. After setting time limitations for the quiz, teachers decide on the type of the questions. There exists five alternatives; Multiple Choice, True/False, Short Answer, Fill in the blank, and Matching.

Figure 5: Different Question Formats of the Platform

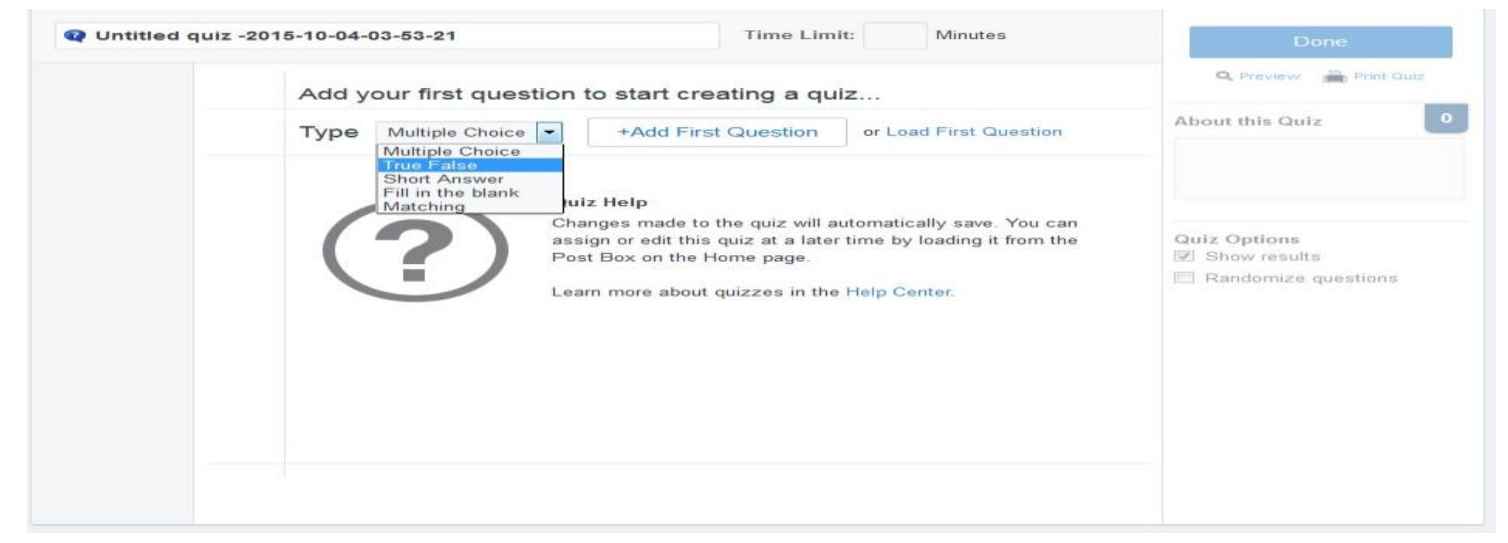

As it is clear from the screenshot above, teachers can easily add questions in various format or they can load a previously created question by means of 'Load First Question' button. Some examples from an EFL class are presented in the following screenshots; 
Figure 6: An Example for Multiple Choice Question Types

\begin{tabular}{|c|c|c|c|c|}
\hline \multicolumn{3}{|c|}{ Untitled quiz -2015-04-14-05-03-59 } & \multicolumn{2}{|c|}{ (t) $58: 53$ left } \\
\hline QUESTIONS & \multicolumn{2}{|c|}{ Question 1} & $<$ & $>$ \\
\hline \multirow[t]{7}{*}{$\square 1$} & & & \multicolumn{2}{|c|}{ Question Total: 5 points } \\
\hline & \multicolumn{2}{|c|}{ 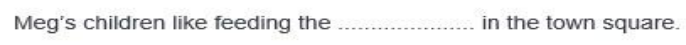 } & & \\
\hline & A & ants & & \\
\hline & B & butterflies & & \\
\hline & c & rhinos & & \\
\hline & $\mathbf{D}$ & goats & & \\
\hline & E & pigeons & & \\
\hline
\end{tabular}

Figure 7: An Example for True/False Question Types

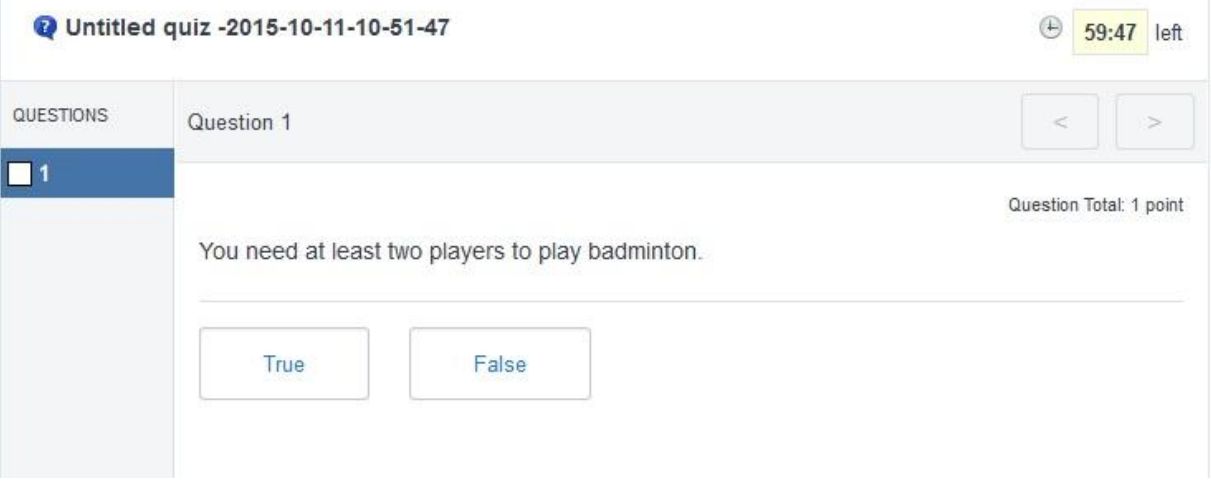

Figure 8: An Example for Short Answer Question Types
(2) Untitled quiz -2015-10-11-12-26-09
(ㄴ) $59: 55$ left

\begin{tabular}{l|l|l|} 
QUESTIONS & Question 1 & $<$ \\
\hline$\square 1$ & Have you ever been abroad? & Question Total 1 point \\
\hline$\square 2$ & \\
\hline$\square 3$ & \\
\hline & \\
\hline & \\
\hline
\end{tabular}


Figure 9: An Example for Fill in the blank Question Types

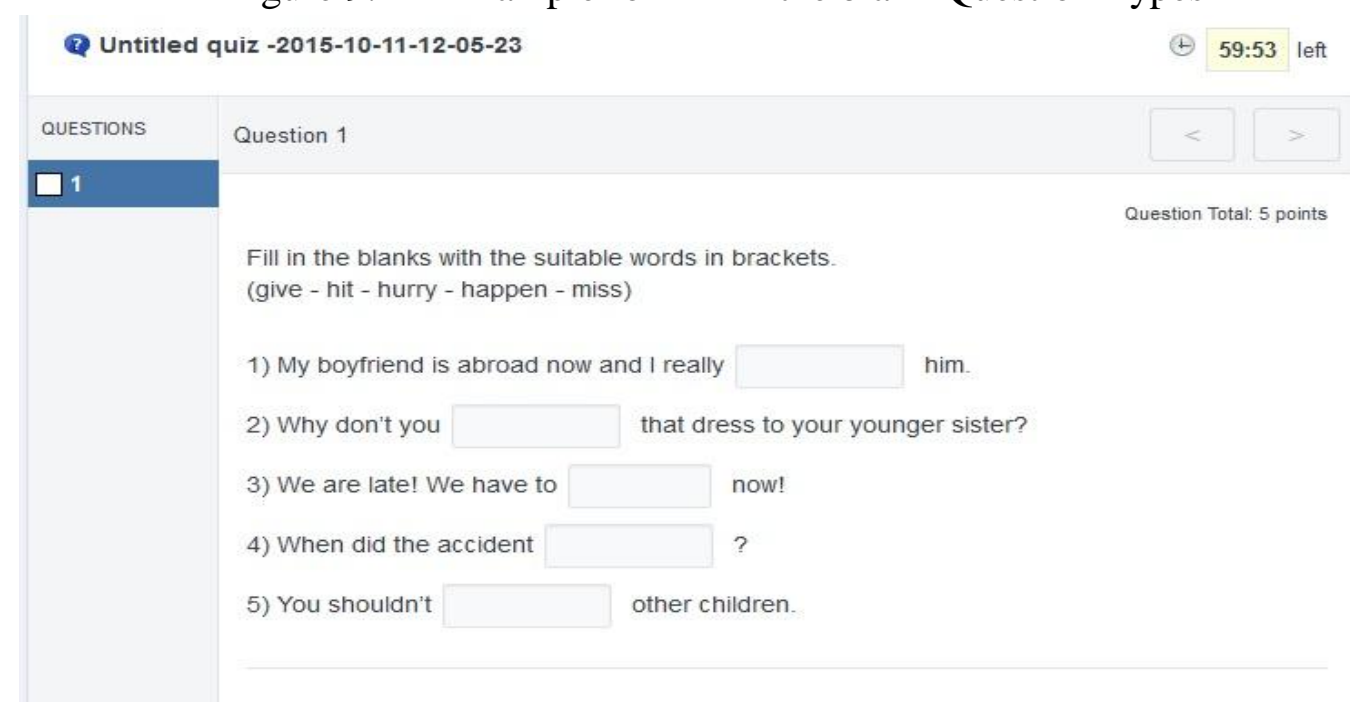

Figure 10: An Example for Matching Question Types

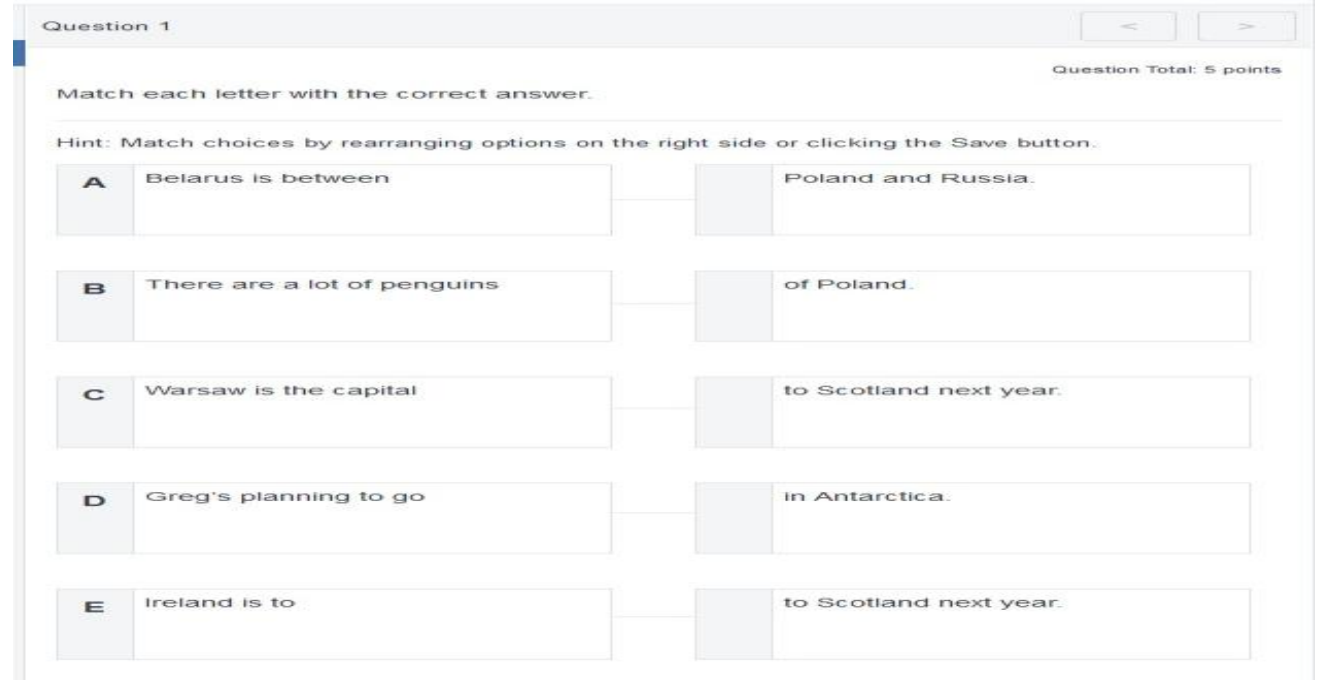

As it is obvious from the screenshots above, Edmodo provides teachers with various assessment facilities in language classes. Teachers can employ both formative and summative assessment techniques through online exams. Some specific grammar structures, vocabulary, reading and listening comprehension skills can be assessed by means of easily-created quizzes. Duration of each quiz can be set and results can be sent to each student by just clicking a button.

\section{Students' views on Edmodo}

In this part, accounts of previous experiences and some reflections of students are presented. 62 students attending English preparatory classes in a state university in Turkey participated in various assessment activities through Edmodo during 2014-2015 academic year. An instructor of English teaching in vocabulary and reading classes conducted the study. Students having studied the related vocabulary items and reading texts in face-to-face 
traditional classes were taken to language lab to be given online quizzes after each module. Matching, true/false, fill in the blanks, short answers and multiple choice question types were all included in different quizzes conducted during an academic year. Results were shared with the students immediately after each quiz and students were given oral feedback about their mistakes. Overall success rates of the students were also determined statistically and shared with the students. At the end of the academic year, a semi-structured interview was conducted by the researcher. Four questions were posed to the students; 1. Do you think Edmodo is an effective tool for assessment? 2. What are the pros of using Edmodo in your class? 3. What are the cons of using Edmodo in your class? 4. Which assessment type would you prefer if you had a chance? Pen and paper quizzes or online quizzes.

\section{Results of the semi-structured interview}

\section{Do you think Edmodo is an effective tool for assessment?}

56 students out of 62 gave positive answer to this question. Only 4 students thought that Edmodo is not an effective assessment tool. 2 students were undecided. The related graph is below:

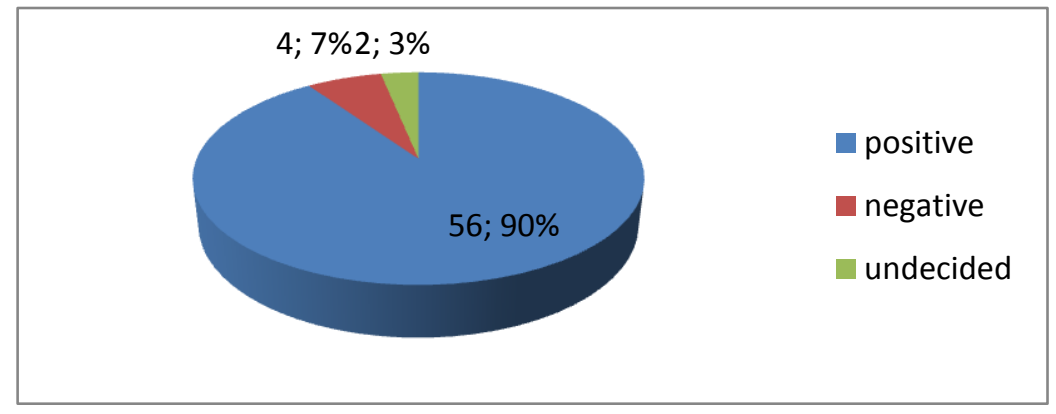

Graph 1: Percentage of students' opinion about the effectiveness of Edmodo

\section{What are the pros of using Edmodo in your class?}

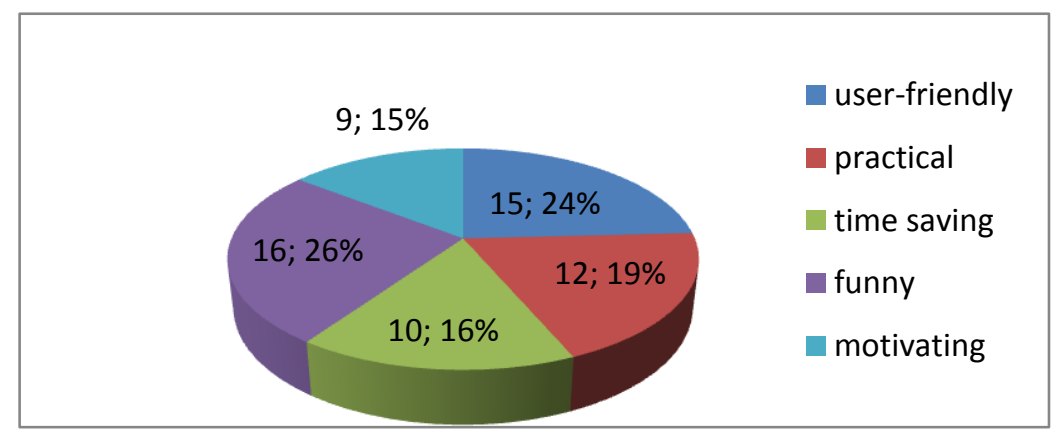

Graph 2: Percentage of students' opinion about the pros of using Edmodo

The graph above indicates the number and percentage of students who answered the second question regarding the pros of using Edmodo. 15 students stated that Edmodo is userfriendly, 12 of them reported that it is practical and 10 students focused on its time-saving aspect. 16 students found Edmodo funny and 9 thought that it is motivating for students 


\section{What are the cons of using Edmodo in your class?}

In the semi-structured interview, students were asked about the cons of using Edmodo as an assessment tool. 46 students (74\%) stated that there were no drawbacks of using Edmodo while being assessed. 11 students reported that as it requires internet connection, it is not so practical. Few students complained about slowness of the platform. Only two students stated that Edmodo is confusing. The related graph is presented below:

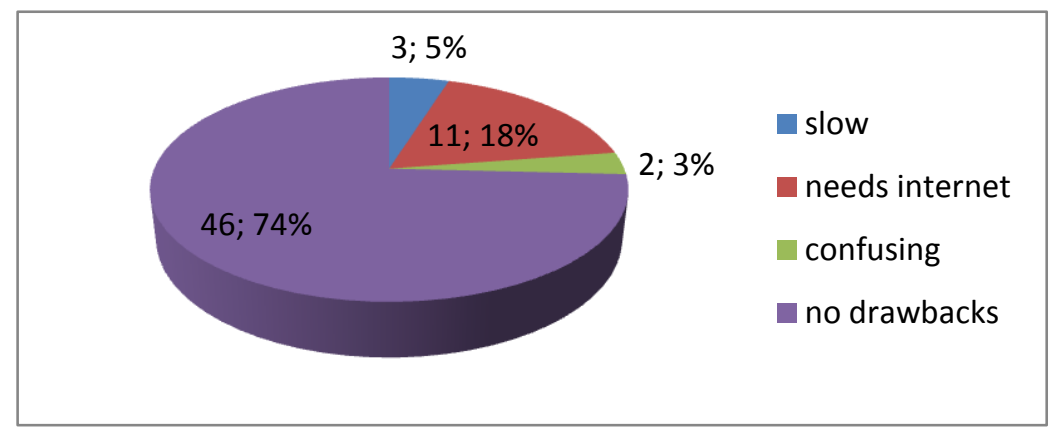

Graph 3: Percentage of students' opinion about the cons of using Edmodo

\section{4. . Which assessment type would you prefer if you had a chance? Pen and paper quizzes or online quizzes.}

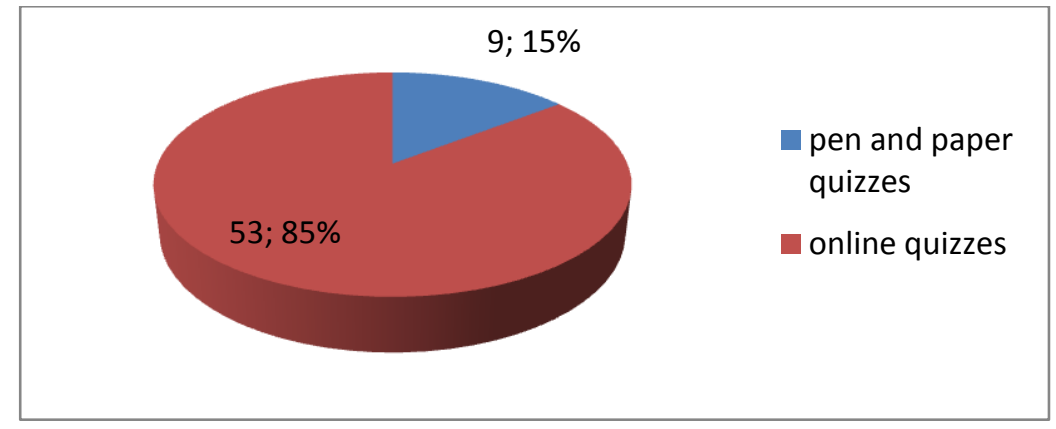

Graph 4: Percentage of students' prefeences about the assessment types

As it is clear from the graph above, a great number of students (n:53) reported that they would prefer online quizzes to pen and paper quizzes. Only 9 students stated that they would prefer pen and paper quizzes if they had a chance. As a response to this question, students also stated that they feel less test anxiety in online quizzes compared with pen and paper ones. Excerpts of some students' speech are as follows:

S1: "I prefer online quizzes, because I feel more relaxed and secure during online quizzes" S2: "Normally I get excited in all exams. However, I really feel comfortable in online quizzes"

S3: "I don't like pen and paper quizzes. I feel nervous and I forget everything, but I believe that online quizzes help me reduce my test anxiety"

\section{Conclusion}

The current study introduces EDMODO as an alternative assessment tool to traditional pen and paper assessment techniques. Being a free of charge learning platform, Edmodo can 
provide all subject teachers in general and language teachers in particular with various assessment facilities. The study shows the steps of how to create a free account and form groups in Edmodo. The overall aim of the study is to indicate that Edmodo can be used as an effective assessment techniques as well as a learning platform through which teachers can share course materials, notes, links and documents. In addition, the current study having introduced the basic steps of creating a free account and student groups, it demonstrates how to prepare quizzes with different question types which language teachers can easily produce. To this end, accounts of previous experiences and some reflections of students are presented. 62 students attending English preparatory classes in a state university in Turkey participated in various assessment activities through Edmodo during 2014-2015 academic year. Reflections of the students regarding the use of Edmodo as an assessment tool were obtained through semi-structured interviews conducted by the researcher. In relation to the findings, 90 $\%$ of the students participated in the study stated that the platform can be employed as an assessment tool in language classes. As the advantages of the platform, the students regarded Edmodo as user-friendly, practical, time-saving, funny, and motivating. However, $25 \%$ of the students showed negative reactions towards Edmodo stating that it is slow, confusing, and requires constant internet connection. In addition, $85 \%$ of the students stated that they would prefer online quizzes rather than pen and paper ones. Transcriptions of the students presented above also indicate that most of the students think that online exams reduce their test anxiety compared with the traditional ones. The findings of the study are also in line with what Govender and Grayson (2007) and Dalton (2009) report in the literature. Considering all the results obtained from semi-structured interview, it can be concluded that Edmodo can function as an effective assessment tool in language classrooms. With its immediate feedback and user-friendly aspects, it can serve as an alternative assessment tool to traditional pen and paper exams in the classroom.

\section{References}

Aldhafri, S., Alkharusi, H., \& Al Ismaili, A. (2015). Predicting english test anxiety: how memorization and critical thinking function? Theory and Practice in Language Studies, 5(6), 1159-1165.

Al-Said, K. M. (2015). Students' perceptions of edmodo and mobile learning and their real barriers towards them. The Turkish Online Journal of Educational Technology, 14(2), 167-180.

Aydin, S. (2013). Factors affecting the level of test anxiety among efl learners at elementary schools. E-international journal of educational research, 4(1), 63-81.

Balasubramanian, K., Jaykumar, V., \& Fukey, L. N. (2014). A study on "student preference towards the use of edmodo as a learning platform to create responsible learning environment". Procedia Social and Behavioral Sciences, 144(1), 416-422.

Batsila, M., Tsihouridis, CH., \& Vavougios, D. (2014). Entering the Web-2 Edmodo World to Support Learning: Tracing Teachers' Opinion after Using it in their Classes. iJET, 9(1), 53-60, http://dx.doi.org/10.3991/ijet.v9i1.3018.

Cheng, L. and Klinger, D., Fox, J., Doe, C., Jin, Y., \& Wu, J. (2014). Motivation and test anxiety in test performance across three testing contexts: The CAEL, CET, and GEPT. TESOL Quarterly, 48(2), 300-328.

Conradie, P.,Moller, M., \& Faleni, T. (2014). The effect of learning management systems' media richness on 21st century student's satisfaction: A higher education perspective. $13^{\text {th }}$ European Conference on e-Learning - ECEL 2014.

Dalton, J. (2009). Teaching and learning through social networks. Retrieved from www.teachingenglish.org.uk.print/5411 
Dogoriti, E., \& Pange, J. (2014). Instructional design for a "social" classroom: Edmodo and twitter in the foreign language classroom. ICICTE 2014 Proceedings, 154-165.

Govender, I., \& Grayson, D. J. (2007). Pre-service and in-service teachers' experiences of learning to program in an object-oriented language, Computers \& Education, 51(2), 874-885.

Horvat, A., Dobrota, M., Krsmanovic, M., \& Cudanov, M. (2015). Student perception of Moodle learning management system: a satisfaction and significance analysis, Interactive Learning Environments, 23(4), 515-527, DOI: 10.1080/10494820.2013.788033.

Huang, H. D., \& Hung, S.A. (2013). Comparing the effects of test anxiety on independent and integrated speaking test performance. TESOL Quarterly, 47(2), 244 - 269.

Lane, L. (2009). Insidious pedagogy: How course management systems affect teaching First Monday, 14. Retrieved from http://firstmonday.org/ojs/index.php/fm/article/view/2530/2303.

Lee, S.P., \& Lee, S.H. (2015). Effects of audio-visual aids on foreign language test anxiety, reading and listening comprehension, and retention in EFL learners. Perceptual \& Motor Skills: Perception. 120 (2), 576 - 590.

Naveh, G., Tubin, D., \& Pliskin, N. (2010). Student LMS use and satisfaction in academic institutions: The organizational perspective. Internet and Higher Education, 13(3), 127133.

Ractham, P., \& Chen, C. (2013). Promoting the use of online social technology as a casebased learning tool. Journal of Information Systems Education, 24(4), 291-297.

Salahi, M., \& Marefat, F. (2014). The effects of foreign language anxiety and test anxiety on foreign language test performance. Theory and Practice in Language Studies. 4(5), 931 $-940$. 